\title{
Maternal IQ, Child IQ, Behavior, and Achievement in Urban 5-7 Year Olds
}

\author{
AIMIN CHEN, DONALD SCHWARZ, JERILYNN RADCLIFFE, AND WALTER J. ROGAN
}

\begin{abstract}
Epidemiology Branch [A.C., W.J.R.], National Institute of Environmental Health Sciences, National Institutes of Health, Department of Health and Human Services, Research Triangle Park, North Carolina 27709; Department of Adolescent Medicine [D.S.], Children's Hospital of Philadelphia, Philadelphia, Pennsylvania 19104; Department of Psychology [J.R.], Children's Hospital of Philadelphia and University of Pennsylvania School of Medicine, Philadelphia, Pennsylvania 19104
\end{abstract}

\begin{abstract}
In one study of children in 27 families with maternal retardation, those children with higher intelligence quotient (IQ) were more likely to have multiple behavior problems than those with lower IQ. If true, this result would affect clinical practice, but it has not been replicated. Because the setting of the initial observation is similar to the setting of childhood lead poisoning, we attempted a replication using data from the Treatment of Lead-Exposed Children (TLC) study, in which 780 children aged 12-33 mo with blood lead levels $20-44 \mu \mathrm{g} / \mathrm{dL}$ were randomized to either succimer treatment or placebo and then followed up to $5 \mathrm{y}$. Of 656 mothers of TLC children with IQ measured, 113 demonstrated mental retardation (IQ $<70$ ). Whether maternal IQ was $<70$ or $\geq 70$, children with IQ $\geq 85$ were rated more favorably on cognitive tests and behavioral questionnaires than children with IQ $<85$; these measures included Conners' Parent Rating Scale-Revised at age 5, the Developmental Neuropsychological Assessment at ages 5 and 7, and the Behavioral Assessment System for Children at age 7. Among children of mothers with IQ $<70$, those with IQ $\geq 85$ did not show more severe clinical behavioral problems, nor were they more likely to show multiple behavior problems. Children with higher IQ have fewer behavior problems, irrespective of the mother's IQ. In the special setting of mothers with IQ $<70$, children with higher IQ are not at greater risk of behavior problems. (Pediatr Res 59: 471-477, 2006)
\end{abstract}

$\mathrm{T}^{\mathrm{s}}$ he relation of maternal IQ with child IQ and child behavior is not well studied in families with maternal mental retardation. In 1997, Feldman and Walton-Allen (1) reported that children of mothers with mental retardation living in poverty had more behavior problems and lower IQ than children from similar families but without maternal mental retardation. In addition, they advanced the hypothesis that, among studied children in families with maternal mental retardation, those with higher IQ were more likely to have multiple behavior problems than those with lower IQ. They based this conclusion on their observation that, among the 27 families with maternal mental retardation, none of the 11

Received June 21, 2005; accepted October 25, 2005.

Correspondence: Walter J. Rogan, M.D., Epidemiology Branch, NIEHS, M.D. A3-05, P.O. Box 12233, Research Triangle Park, NC 27709; e-mail: rogan@niehs.nih.gov

Presented, in part, at the annual meeting of the Pediatric Academic Societies, May 14-17, 2005, Washington, DC.

The Treatment of Lead-Exposed Children Trial was supported by the NIEHS in cooperation with the NIH Office of Minority Health, and by the Centers for Disease Control and Prevention. Succimer and placebo capsules were gifts from McNeil Labs, Fort Washington, PA.

DOI: 10.1203/01.pdr.0000199910.16681.f0 children with IQ $<85$ scored above the clinical threshold on all three subscales (conduct, hyperactivity, and emotional) of the Ontario version of the Child Behavior Checklist, whereas 5 of the children with IQ of 85 or greater did. The authors speculated that, because parents with mental retardation may not set reasonable limits for and communicate well with their more intelligent children, these children may take advantage of, and rebel against, less competent parents (1). Early antisocial acts against authorities may also develop (2).

If this hypothesis were true, it would influence clinical practice by focusing attention more on brighter children living in poverty and with mothers with cognitive limitations, because children with higher IQ are not usually thought to be at high risk for behavioral or academic problems (3-5). Because of these clinical implications, we sought to replicate Feldman's finding in another setting in which many relatively disadvantaged families are found-that of urban lead poisoning. We had done a large clinical trial of the treatment of lead poisoning in which we measured maternal IQ, and did multiple measures of child IQ and behavior over $5 \mathrm{y}$ of follow-up. We use data from that trial to attempt a direct replication of Feldman's finding, and to explore further the interrelationships among maternal IQ, child IQ, and child behavior.

\section{METHODS}

The TLC study was a multicenter, randomized, placebo-controlled clinical trial to investigate the effect of treatment with succimer, an oral lead chelator, on IQ, neuropsychological, and behavioral measurements 36 mo after the initiation of treatment (6). Altogether, 780 children aged 12-33 mo with blood lead concentrations of $20-44 \mu \mathrm{g} / \mathrm{dL}$ were randomized to succimer or placebo between August 1994 and January 1997 at four clinical centers: Baltimore, MD, Newark, NJ, Philadelphia, PA, and Cincinnati, OH. Three hundred ninety-six children were randomly assigned to succimer and 384 to placebo. Depending on the blood lead, children in the succimer group could receive up to three 26-d courses of treatment; the number of courses given to placebo children was frequency matched to that in the succimer group. The succimer

Abbreviations: BASC-PRS, Behavioral Assessment System for ChildrenParent Rating Scale; BASC-TRS, Behavioral Assessment System for Children-Teacher Rating Scale; CPRS-R, Conners' Parent Rating Scale-Revised; CPT, Conners' Continuous Performance Test; CVLTC, California Verbal Learning Test for Children; IQ, intelligence quotient; NEPSY, Developmental Neuropsychological Assessment; NESS, Neurological Examination for Subtle Signs; TLC, Treatment of Lead-Exposed Children Study; WLPB-R, Woodcock Language Proficiency Battery-Revised 
group had a lower blood lead concentration for about $6 \mathrm{mo}$, but did not show any difference in IQ, neuropsychological, or behavior tests at 36 mo of follow-up (7). An extension of the study to 60 mo of follow-up confirmed the main results (8). Inasmuch as succimer treatment did not affect test scores, we combined across treatment groups for the analysis of maternal IQ, child IQ, behavior, achievement, and neuropsychological function. The study was approved by the institutional review boards at the clinical centers, the Harvard School of Public Health, the Centers for Disease Control, and the National Institute of Environmental Health Sciences. The parents of all the children provided written informed consent at enrollment.

Of 780 children who participated in the trial, 745 had caregiver's IQ measured with the Wechsler Adult Intelligence Scale-Revised (9), among whom were 656 mothers. In this analysis, only data from the 656 children of these mothers were used. The child's full-scale IQ was measured with the Wechsler Preschool and Primary Scales of Intelligence-Revised (WPPSI-R) (10) at 36 mo of follow-up (about age 5) and with the Wechsler Intelligence Scale for Children-III (WISC-III) (11) (at age 7 y). The neuropsychological and behavioral tests used at age 5 included the Developmental Neuropsychological Assessment (NEPSY) (12) and Conners' Parent Rating Scale-Revised (CPRS-R) (13), and that used at age 7 were NEPSY (12), Conners' Continuous Performance Test (CPT) (14), California Verbal Learning Test for Children (CVLTC) (15), Woodcock Language Proficiency Battery-Revised (WLPB-R) (16), Neurologic Examination for Subtle Signs (NESS) (17), Behavioral Assessment System for Children teacher rating scale (BASCTRS), and BASC parent rating scale (BASC-PRS) (18). The administration of CPRS-R at age 5 and BASC-PRS at age 7 by parents was completed by trained examiners reading aloud questions to parents and providing clarification of items as necessary; examiners were blind to maternal IQ levels. Blood lead concentrations were measured by atomic absorption spectrometry based on the methods described by Miller et al. (19).

As a first step in using data from the trial to test whether children with higher IQ who had mothers with mental retardation showed more behavior problems, we replicated Feldman's approach, comparing the neuropsychological and behavioral test scores of children with higher $(\geq 85)$ or lower $(<85)$ IQ scores, given maternal IQ $<70$. We did a similar analysis among children with maternal IQ $\geq 70$. We then compared percentage of children being "at risk" for "clinically significant" problems (CPRS-R indices or BASC problem scores $\geq 60$ ) and percentage of children having "clinically significant" problems (CPRS-R indices or BASC problem scores $\geq 70$ ) across child IQ categories. In addition, we examined the more general finding that children with mentally retarded mothers had lower IQ, poorer school achievement, and more behavior problems. The covariates used for adjustment, determined a priori based on the literature (20-22), were clinic center (Baltimore, Newark, Philadelphia, and Cincinnati), race (black, white, and others), gender (male, female), language (English or Spanish), parents' education (under $12 \mathrm{y}, 12 \mathrm{y}$, over $12 \mathrm{y}$ ), parents' employment (neither working, either working), single parent (yes, no), concurrent blood lead level (5 or $7 \mathrm{y}$ ), and maternal IQ.

Finally, we attempted to assess the relative contributions of maternal IQ, child's IQ, and both on neuropsychological, behavioral, and achievement scores. We made three sets of statistical models, all of which included behavior, neuropsychological, or achievement scores as dependent variables. As independent variables, the models used either maternal IQ (model 1), child's IQ (model 2), or both (model 3), and all included the covariates clinical center, race, sex, language, parents' education, parents' employment, single parent, and concurrent blood lead level. SAS 9.0 (SAS Institute Inc. Cary, NC) was used for all statistical analyses.

\section{RESULTS}

The mothers and children in these data were predominantly from low socioeconomic status families (Table 1). The 656 children with maternal IQ tested did not differ in baseline characteristics from the other children of the total 780 recruited. Their mean age was about $2 \mathrm{y}$ at baseline, thus $5 \mathrm{y}$ at 36 mo of follow-up and $7 \mathrm{y}$ at last follow-up.

The mean $( \pm \mathrm{SD})$ of maternal IQ in the 656 children's mothers was $80 \pm 11 ; 113(17 \%)$ had IQ $<70$ (mean \pm SD: $65 \pm 4$ ) and $543(83 \%)$ had IQ $\geq 70$ (mean \pm SD: $83 \pm 10$ ). At about age 5, 624 children had IQ tested, with mean \pm SD of $81 \pm 13$; at age 7, 549 children had IQ tested, with mean $\pm \mathrm{SD}$ of $86 \pm 13$. The correlation coefficient of maternal IQ
Table 1. Demographic characteristics and blood lead levels of 656 TLC children at baseline and follow-ups

\begin{tabular}{lc}
\hline \multicolumn{1}{c}{ Characteristics } & \% or mean \pm SD \\
\hline Clinic center & 29 \\
Baltimore & 26 \\
Newark & 20 \\
Philadelphia & 24 \\
Cincinnati & 77 \\
African-American & 54 \\
Boys & 95 \\
English-speaking & 40 \\
Parent's education $<12$ y & 59 \\
Neither parent working & 74 \\
Living with single parent & 51 \\
Succimer (treatment) group & \\
Blood lead level ( $\mu$ g/dL) & $26 \pm 5$ \\
Baseline $(n=656)$ & $12 \pm 5$ \\
36 mo follow-up ( $n=628)$ & $8 \pm 4$ \\
60 mo follow-up ( $n=530 *$ ) & \\
Age (y) & $2.0 \pm 0.5$ \\
Baseline & $5.0 \pm 0.5$ \\
36 mo follow-up blood lead and IQ & $5.1 \pm 0.5$ \\
36 mo follow-up CPRS-R & $5.2 \pm 0.5$ \\
36 mo follow-up NEPSY & $7.0 \pm 0.2$ \\
60 mo follow-up blood lead & $7.1 \pm 0.2$ \\
60 mo follow-up IQ, CVLTC, and BASC-PRS & $7.3 \pm 0.4$ \\
60 mo follow-up BASC-TRS & $7.5 \pm 0.2$ \\
60 mo follow-up NEPSY, CPT, WLPB-R, and NESS & \\
\hline & \\
\hline &
\end{tabular}

* One child with unexpectedly high blood lead level of $51 \mu \mathrm{g} / \mathrm{dL}$ at $60 \mathrm{mo}$ follow-up was excluded from the analysis of $7 \mathrm{y}$ outcomes.

and child IQ was 0.31 at age 5 and 0.41 at age 7 ; that of child IQ at age 5 and at age 7 was 0.78 . The $p$ values of the correlation tests are all $<0.001$.

The test scores of NEPSY and CPRS-R at age 5 stratified by maternal IQ $(<70$ or $\geq 70)$ and child IQ at age $5(<85$ or $\geq 85)$ as well as the difference of scores between two child IQ categories are shown in Table 2. Analogously, scores from NEPSY, CPT, CVLTC, WLPB-R, NESS, BASC-TRS, and BASC-PRS at age 7 are shown in Table 3. Not all children completed all tests and so the numbers vary slightly. The tables show the adjusted differences between child IQ categories. The difference between the maternal IQ categories can be obtained by subtracting the comparable columns under each maternal IQ category. If we look at the CPRS-R in the 5 -y-olds of the lower IQ mothers, the higher IQ children show better mean behavior scores than the lower IQ children. The pattern is the same for the higher IQ mothers, and the size of the differences between the children with different IQ scores is the same, independent of their mother's IQ. At age 7, the pattern is the same, with one exception-"internalizing problems" on the BASC parent scale is at the same level for higher and lower IQ children stratified by maternal IQ category. In these data, then, higher IQ children generally had fewer behavior problems than lower IQ children in both maternal IQ categories.

The percentages of children with behavior test scores $\geq 60$ or $\geq 70$ are shown in Table 4 . With either of the clinical cut-off points, children with IQ $<85$ generally had more behavior problems (some comparisons achieve statistical significance) at a clinical level than their higher IQ peers, given equivalent 
Table 2. Neuropsychological and behavioral test scores at age 5 by maternal IQ and child 5-y IQ

\begin{tabular}{|c|c|c|c|c|c|c|c|c|c|c|}
\hline \multirow{2}{*}{$\begin{array}{l}\text { Neuropsychological and } \\
\text { behavioral test at age } 5\end{array}$} & \multicolumn{5}{|c|}{ Maternal IQ <70 } & \multicolumn{5}{|c|}{ Maternal IQ $\geq 70$} \\
\hline & \multicolumn{2}{|c|}{ Child 5-y IQ < 85 } & \multicolumn{2}{|c|}{ Child 5-y IQ $\geq 85$} & $\frac{\text { Difference* }^{*}}{\beta(\mathrm{SE})}$ & \multicolumn{2}{|c|}{ Child 5-y IQ <85 } & \multicolumn{2}{|c|}{ Child 5-y IQ $\geq 85$} & $\frac{\text { Difference* }^{*}}{\beta(\mathrm{SE})}$ \\
\hline \multicolumn{11}{|l|}{ NEPSY } \\
\hline Attention and executive & 72 & $80 \pm 19$ & 25 & $93 \pm 17$ & $13.7(4.5)$ & 245 & $83 \pm 18$ & 222 & $94 \pm 16$ & $9.9(1.7)$ \\
\hline Visuospatial & 76 & $84 \pm 12$ & 25 & $96 \pm 10$ & $10.0(2.9)$ & 260 & $85 \pm 11$ & 225 & $97 \pm 11$ & $10.8(1.1)$ \\
\hline Memory & 77 & $77 \pm 14$ & 24 & $93 \pm 13$ & $13.4(3.3)$ & 252 & $84 \pm 14$ & 219 & $97 \pm 12$ & $11.0(1.3)$ \\
\hline \multicolumn{11}{|l|}{ CPRS-R } \\
\hline Oppositional index & 83 & $61 \pm 15$ & 25 & $56 \pm 14$ & $-4.8(3.5)$ & 282 & $59 \pm 14$ & 226 & $55 \pm 13$ & $-4.4(1.3)$ \\
\hline Hyperactivity index & 83 & $67 \pm 14$ & 25 & $62 \pm 13$ & $-4.0(2.8)$ & 282 & $65 \pm 14$ & 226 & $61 \pm 14$ & $-2.6(1.2)$ \\
\hline ADHD index & 83 & $62 \pm 13$ & 25 & $56 \pm 11$ & $-5.5(2.7)$ & 282 & $63 \pm 13$ & 226 & $57 \pm 12$ & $-5.8(1.1)$ \\
\hline
\end{tabular}

* Difference is the difference of child 5-y IQ $\geq 85$ minus child 5-y IQ $<85$, adjusted for clinic center, race, sex, language, parents' education, parents' employment, single parent, concurrent blood lead level, and maternal IQ.

Table 3. Neuropsychological and behavioral test scores at age 7 by maternal IQ and child 7-y IQ

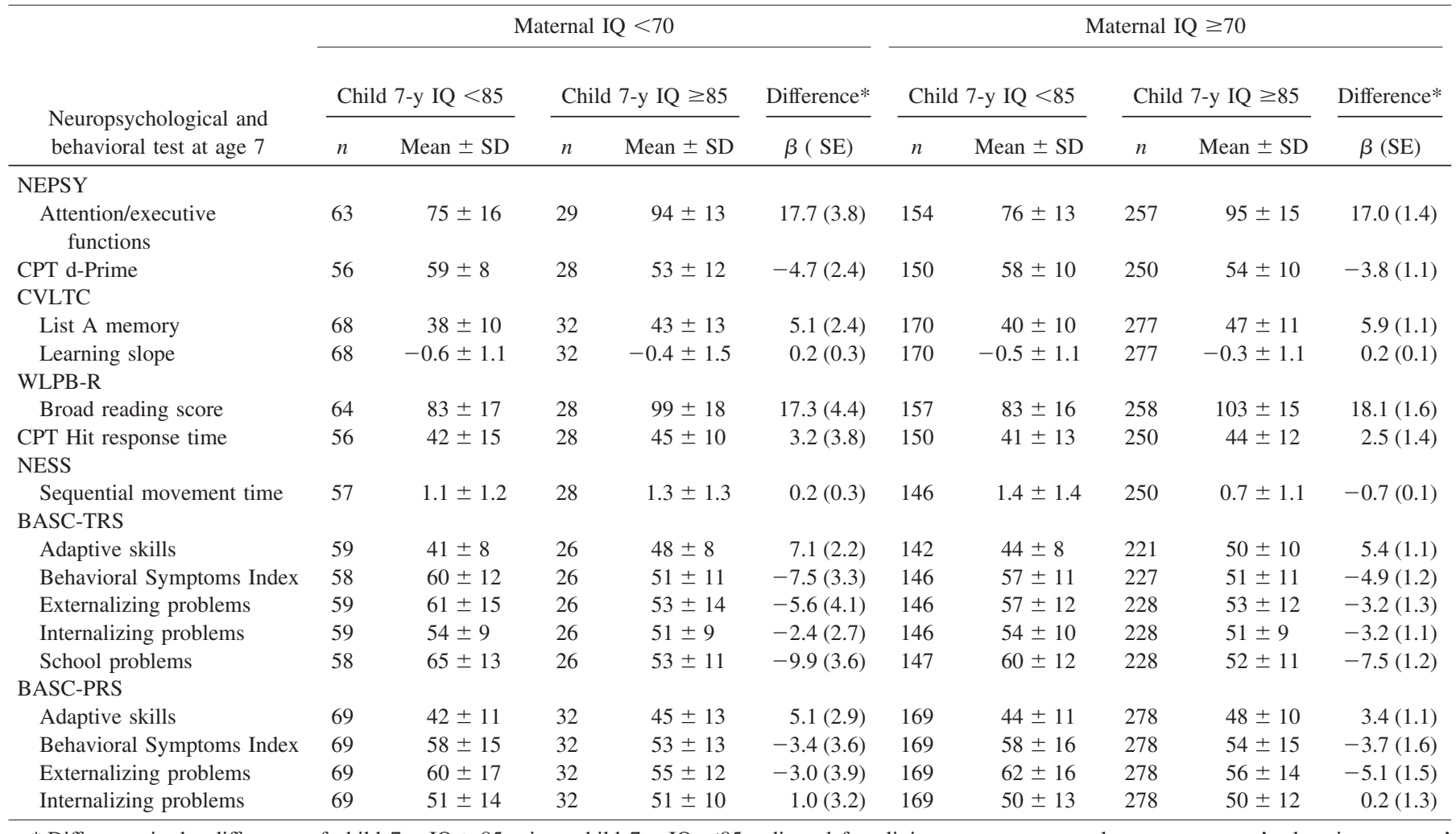

* Difference is the difference of child 7-y IQ $\geq 85$ minus child 7-y IQ $<85$, adjusted for clinic center, race, sex, language, parents' education, parents' employment, single parent, concurrent blood lead level, and maternal IQ.

maternal IQ. Among children with maternal IQ $<70$, the percentage of having both externalizing and internalizing problems, an indicator similar to "multiple behavior problems" in the Feldman paper (1), did not differ statistically between children with IQ $<85$ and IQ $\geq 85$; this is also true for children with maternal IQ $>70$ (Table 4).

BASC scores from both the teacher rating scale and the parent rating scale were checked to see if agreement between teachers and parents was similar for mothers with IQ $<70$ and mothers with IQ $\geq 70$. The correlation coefficients between teacher and parent reports were 0.26 for adaptive skills, 0.21 for behavioral symptoms index, 0.35 for externalizing problems, and -0.10 for internalizing problems in mothers with IQ $<70$, and in mothers with IQ $\geq 70$, these correlation coefficients were $0.33,0.29,0.36$, and 0.16 , respectively. The mean differences between teacher- and parent-rated scores (parent score minus teacher score) ranged from -2.32 to 3.19 , all $<0.3$ $\mathrm{SD}$ of these scores, with no statistically significant difference between mothers with IQ $<70$ and mothers with IQ $\geq 70$. For the percentage of children with BASC scores $\geq 60$ or $\geq 70$ in 
Table 4. Percentage of behavior test scores $\geq 60$ and $\geq 70$ by maternal $I Q$ and child $I Q$ at the age of behavior tests

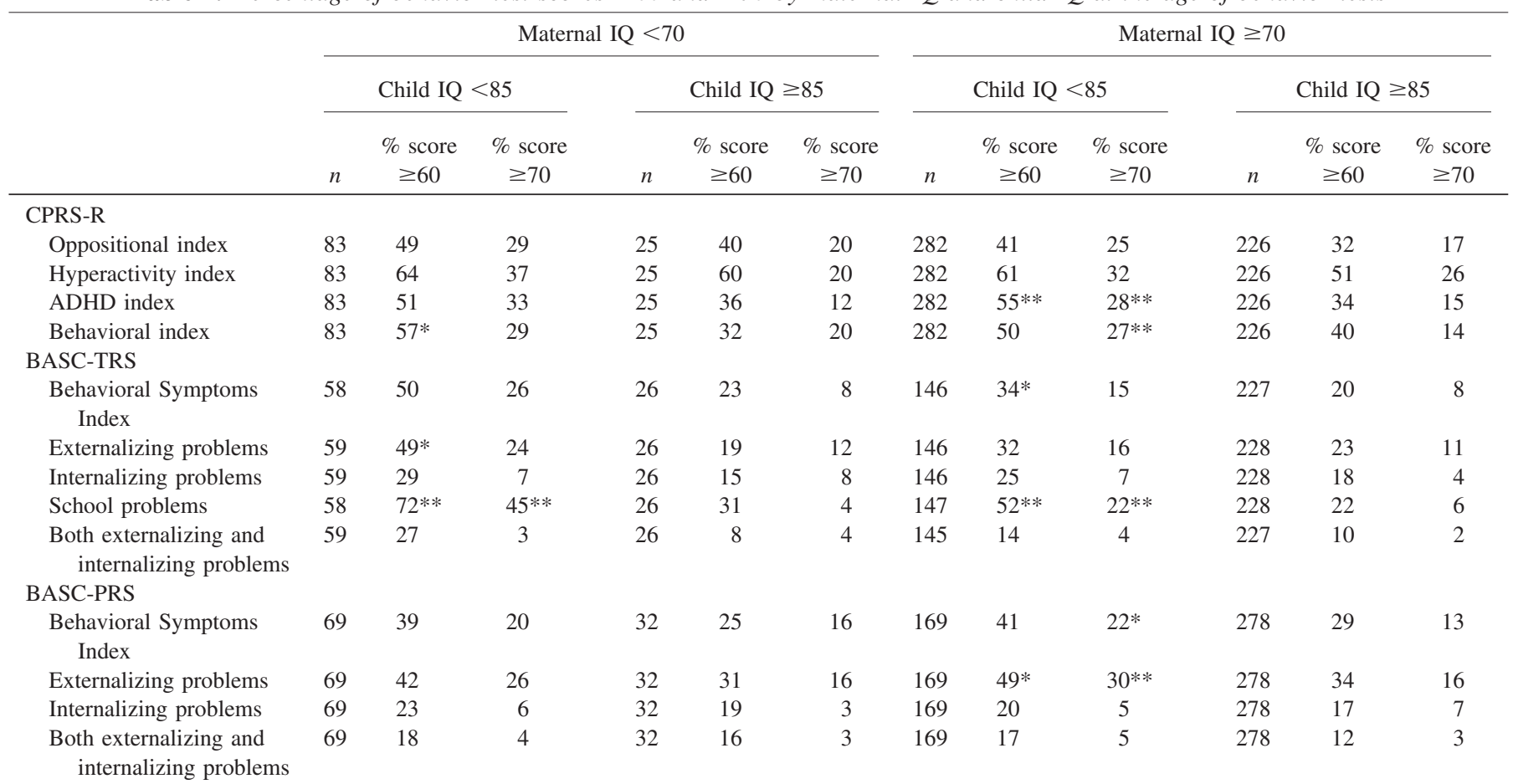

$* p<0.05, * * p<0.01$ for comparison with children with IQ $\geq 85$ under the same maternal IQ category, after adjustment for clinic center, race, sex, language, parents' education, parents' employment, single parent, and concurrent blood lead level.

the behavioral symptoms index and externalizing problems, the kappa statistics between teacher and parent report were similar for mothers with IQ $<70$ and mothers with IQ $\geq 70$ (kappa 0.13 to 0.28 ). However, for BASC scores $\geq 60$ or $\geq 70$ in internalizing problems and both externalizing and internalizing problems, the kappa statistics between teacher and parent reports were lower (kappa -0.05 to 0.06 ) in mothers with IQ $<70$ than in mothers with IQ $\geq 70$ (kappa 0.10-0.14).

The results of general linear models on the association of maternal IQ and child IQ with the other test scores at ages 5 and 7 are shown in Table 5 and Table 6, respectively. For tests at $5 \mathrm{y}$, maternal IQ was positively and significantly correlated to NEPSY domains but not to CPRS-R indices. The child's own IQ had an effect about twice as large on the NEPSY domains, and children with higher IQ had significantly fewer behavior problems on the CPRS-R. When both maternal and child IQ are considered (model 3), child IQ remained statistically significant, with regression estimates largely similar to those in model 2, but maternal IQ only had significance on NEPSY language and memory scores and then with smaller regression estimates. At age 7, there is a similar picture, with small effects from maternal IQ that are marginally or not statistically significant, larger positive effects from child IQ, and a reduction of the maternal effect with a persistence of the child effect when both are in the model. This finding holds consistently for neuropsychological testing (NEPSY), behavior (the BASCs) and achievement (WLPB-R Broad reading). Additional regression models of maternal IQ and child IQ

Table 5. Neuropsychological and behavioral test scores at age 5 by maternal IQ, child IQ, or both*

\begin{tabular}{|c|c|c|c|c|c|c|}
\hline $\begin{array}{l}\text { Neuropsychological and } \\
\text { behavioral test at age } 5\end{array}$ & $\mathrm{~N}$ & Mean \pm SD & $\begin{array}{c}\text { Model } 1 \\
10 \text { point } \\
\text { Maternal IQ } \\
\beta(\mathrm{SE})\end{array}$ & $\begin{array}{c}\text { Model } 2 \\
10 \text { point } \\
\text { Child 5-y IQ } \\
\beta \text { (SE) }\end{array}$ & \multicolumn{2}{|c|}{ Model 3} \\
\hline \multicolumn{7}{|l|}{ NEPSY } \\
\hline Attention and executive & 565 & $87 \pm 18$ & $2.5(0.8)$ & $5.7(0.6)$ & $0.7(0.7)$ & $5.6(0.7)$ \\
\hline Language & 545 & $84 \pm 14$ & $3.2(0.6)$ & $6.6(0.4)$ & $1.2(0.5)$ & $6.3(0.5)$ \\
\hline Memory & 573 & $88 \pm 15$ & $3.5(0.6)$ & $6.8(0.4)$ & $1.3(0.5)$ & $6.5(0.5)$ \\
\hline \multicolumn{7}{|l|}{ CPRS-R } \\
\hline Oppositional index & 619 & $58 \pm 14$ & $-1.2(0.6)$ & $-1.4(0.4)$ & $-0.8(0.6)$ & $-1.2(0.4)$ \\
\hline Hyperactivity index & 619 & $64 \pm 14$ & $-0.9(0.5)$ & $-1.4(0.4)$ & $-0.4(0.5)$ & $-1.3(0.4)$ \\
\hline ADHD index & 619 & $60 \pm 13$ & $-0.9(0.5)$ & $-2.6(0.4)$ & $0.1(0.5)$ & $-2.6(0.4)$ \\
\hline Behavioral index & 619 & $61 \pm 12$ & $-1.0(0.5)$ & $-1.8(0.4)$ & $-0.4(0.5)$ & $-1.7(0.4)$ \\
\hline
\end{tabular}

* Model 1, model 2, and model 3 all adjusted for clinic center, race, sex, language, parents' education, parents' employment, single parent, and concurrent blood lead level. 
Table 6. Neuropsychological and behavioral test scores at age 7 by maternal IQ, child IQ, or both*

\begin{tabular}{|c|c|c|c|c|c|c|}
\hline $\begin{array}{l}\text { Neuropsychological and } \\
\text { behavioral test at age } 7\end{array}$ & $n$ & Mean $\pm \mathrm{SD}$ & $\begin{array}{c}\text { Model } 1 \\
10 \text { point } \\
\text { Maternal IQ } \\
\beta(\mathrm{SE})\end{array}$ & $\begin{array}{c}\text { Model } 2 \\
10 \text { point } \\
\text { Child } 7-y \text { IQ } \\
\beta(\mathrm{SE})\end{array}$ & \multicolumn{2}{|c|}{ Model 3} \\
\hline \multicolumn{7}{|l|}{ NEPSY } \\
\hline Attention/executive functions & 505 & $87 \pm 17$ & $3.3(0.7)$ & $8.3(0.5)$ & $0.1(0.6)$ & $8.3(0.5)$ \\
\hline CPT d-Prime & 487 & $56 \pm 10$ & $-0.5(0.5)$ & $-2.1(0.4)$ & $0.4(0.5)$ & $-2.2(0.4)$ \\
\hline Learning Slope & 551 & $-0.4 \pm 1.1$ & $0.0(0.1)$ & $0.1(0.0)$ & $0.0(0.1)$ & $0.1(0.0)$ \\
\hline \multicolumn{7}{|l|}{ WLPB-R } \\
\hline Broad reading score & 510 & $94 \pm 19$ & $4.7(0.8)$ & $9.4(0.5)$ & $1.0(0.7)$ & $9.1(0.5)$ \\
\hline CPT Hit response time & 487 & $43 \pm 13$ & $0.3(0.6)$ & $1.2(0.5)$ & $-0.2(0.6)$ & $1.2(0.5)$ \\
\hline \multicolumn{7}{|l|}{ NESS } \\
\hline Sequential movement time & 483 & $1 \pm 1.3$ & $-0.1(0.1)$ & $-0.3(0.0)$ & $0.0(0.1)$ & $-0.3(0.1)$ \\
\hline Internalizing problems & 463 & $52 \pm 10$ & $-0.8(0.5)$ & $-1.5(0.4)$ & $-0.2(0.5)$ & $-1.5(0.4)$ \\
\hline School problems & 463 & $56 \pm 13$ & $-2.8(0.6)$ & $-4.2(0.4)$ & $-1.2(0.6)$ & $-3.9(0.4)$ \\
\hline \multicolumn{7}{|l|}{ BASC-PRS } \\
\hline Adaptive skills & 553 & $46 \pm 11$ & $1.8(0.5)$ & $2.4(0.4)$ & $1.0(0.5)$ & $2.2(0.4)$ \\
\hline Behavioral Symptoms Index & 553 & $56 \pm 15$ & $-1.7(0.7)$ & $-2.3(0.5)$ & $-0.8(0.7)$ & $-2.1(0.6)$ \\
\hline Externalizing problems & 553 & $58 \pm 15$ & $-1.0(0.7)$ & $-2.2(0.5)$ & $-0.2(0.7)$ & $-2.2(0.6)$ \\
\hline Internalizing problems & 553 & $50 \pm 12$ & $-1.2(0.6)$ & $-0.6(0.5)$ & $-1.0(0.6)$ & $-0.3(0.5)$ \\
\hline
\end{tabular}

* Model 1, model 2, and model 3 all adjusted for clinic center, race, sex, language, parents' education, parents' employment, single parent, and concurrent blood lead level.

show the estimate (SE) of 10 point maternal IQ on child IQ was $3.4(0.5)$ points at age 5 and $3.9(0.5)$ points at age 7 after adjustment for the covariates used in Tables 5 and 6 . It is unlikely that maternal IQ accounts for a large proportion of the correlation between child IQ and non-IQ outcomes. Therefore, even considering the association of maternal IQ with child IQ, child IQ remained a strong factor that was correlated with child non-IQ outcomes at both age 5 and age 7 . Higher child IQ was accompanied by better attention and executive function, language proficiency, adaptive skills and by fewer teacher- or parent-reported behavioral problems.

Because these data come from a trial in which half of the children received succimer, an oral chelating drug, for their lead poisoning, we reanalyzed the data by treatment group, and the main results were similar for succimer and for placebo group. We also did an analysis stratified by gender, and the main results did not differ between boys and girls. In no circumstance did the higher IQ children of mothers with lower IQ have significantly more behavior problems than lower IQ children from similar mothers.

\section{DISCUSSION}

The link between maternal cognitive ability and child cognition has been found to be both a genetic and an environmental one (23-26). More recently, the link between maternal cognitive ability and early child behavior has been explored as well (1). The few studies that have looked at children of mentally retarded parents and those of parents of normal intelligence have suggested that parents with mental retardation are more likely to have children with lower cognitive ability, and that those children with higher cognitive ability are more likely to have behavioral problems than children of normal intelligence with parents of normal intelligence $(1,2,27)$.

We found that children with higher IQ were less likely to be "at risk for" or to present with clinically significant behavior problems, irrespective of maternal IQ. This is true at both age 5 and age 7 , and in various behavior domains measured by different behavioral tests. We thus failed to replicate Feldman's finding (1) that higher IQ children of lower IQ mothers have more behavior problems. We also found that mothers with lower IQ are more likely to have children with lower IQ and more behavior problems than mothers of higher intelligence, consistent with previous studies $(27,28)$.

Our study differs from Feldman's in sample size, which may have influenced outcomes. Feldman studied only 27 children from mothers with IQ $<70$, but our study had 108 children with such mothers for CPRS-R at age 5, 85 for BASC-TRS, and 101 for BASC-PRS at age 7. Small clinical samples such as Feldman's may not be representative. Feldman's studied families were referred from community agencies providing advocacy and support services to adults with mental retardation; the mothers were enrolled first. On the other hand, our group of children was selected because of their elevated blood lead concentration. Despite the difference in enrollment strategy, mothers in the Feldman study with mental retardation had mean IQ of 64 (SD 6) whereas mothers in this analysis had mean IQ of 65 (SD 4); they were both of lower IQ and not fundamentally different in intelligence level. Nonetheless, it may be that the relationship between maternal IQ, 
child IQ, and the other psychological tests is different in the lead-exposed children in our study. In the literature, lead exposure was associated with child IQ deficits (29-31) and, though less studied, behavioral problems (20-22). We have multiple measures of their blood lead concentration, and those measures are associated with many of the test scores reported here. We do include the blood lead concentration measured closest to the time of psychological testing, which in these data bear the strongest relationship to test scores, and so the result we see should not be due simply to the effect of lead on both IQ and behavior. Lead exposure is only one of the factors that affect IQ and behavior, and it seems unlikely that lead exposure would bias the IQ and behavior relationship in TLC study because the observed relationship was similar to that in another report in literature (3). It is also plausible that Feldman's subjects were also lead-exposed. The children in Feldman study were older (10 y old) and were tested by the Ontario version of the Child Behavior Checklist (32), but that seems unlikely to cause different results in the two studies.

Another issue is that the accuracy of parent rating scale for those mothers with IQ $<70$ may impact results. When we checked the agreement between teacher and parent BASC ratings for scores at age 7, we found mothers with IQ $<70$ and mothers with IQ $\geq 70$ had similar levels of agreement with teachers for reporting behavior scores except for internalizing problems. The correlation coefficients and kappa statistics between teacher and parent reports in this study are similar to literature reports of parent-teacher behavior ratings of children (33-35). It is unlikely that these mothers (with IQ score of 65) completely lack the ability to report child behavioral problems. The results of teacher-rated scores also confirmed the findings from parent rated scores in our study. Nevertheless, our results suggest that clinicians need to be mindful of the discrepancies between teacher and parent report of internalizing problems in the setting of low maternal IQ. In such situations, clinicians need to ask more specific questions of lower IQ mothers to inquire about symptoms of a child's mental health problems, particularly internalizing problems such as anxiety and depression. Clinicians may also need to ask directly children of mothers with lower IQ about mental health symptoms.

We can speculate about why mother's intelligence level was not as influential as child's IQ in shaping child's behavior patterns. It may be true that lower IQ mothers cannot handle mother-child interaction in an ideal way, but the influence from other family members, neighborhood, community, and school will gain more strength as the child grows, if the child is sufficiently intelligent to allow this societal interaction to take effect. Similarly, among children of parents suffering from psychiatric problems, higher IQ is associated with better personal and social adaptation $(36,37)$.

The relative contributions of maternal IQ and child IQ to child behavior outcomes merit further consideration. In this analysis, the effect of maternal IQ is always smaller than the effect of child IQ on behavior, and when both variables are included in the model, the effect of maternal IQ is very small and not significant. Maternal IQ per se might have some effect on both child IQ and child behavior. In a small data set with two variables that are highly correlated, the analytical model has very few discordant observations to work with, and thus the individual parameters are unstable when both are present in a model. At the extreme, if there are no higher IQ children of lower IQ mothers, the model cannot estimate independent effects. The data set we use, however, is relatively large, and the correlation between maternal and child IQ relatively modest, and thus the model's partitioning of the effect to the child is plausible. It would still be useful to see whether this holds in other data sets. In a sample of 411 13-y-old twins of normal intelligence, Goodman et al. (3) found lower child IQ was associated with more behavioral problems, whereas lower parental IQ (average of maternal and paternal IQ) did not significantly predict behavioral problems. Compared with parental IQ, child IQ may be more powerful in the interrelationship of parental IQ, child IQ, and child behavior. Although it may also be that behavioral problems (e.g. hyperactivity) leads to lower IQ (38), the observation that remission of child psychiatric disorder is not associated with a change in measured IQ suggests child IQ is more likely to be a cause rather than consequence of child behavioral problems (3), probably via poorer ability in dealing with distress or lower self-esteem $(39,40)$.

Overall we conclude that given any maternal IQ, the higher IQ child is always at lower risk for behavior and other problems than the lower IQ child. Among children with similar IQ, maternal IQ does not explain much of the variation in child behavior, neuropsychological function or achievement. These findings support continued efforts to investigate and address factors influencing child cognitive outcomes, such as preventing lead exposure and providing supports to children with lower cognitive ability in an effort to prevent poor behavioral outcomes.

\section{REFERENCES}

1. Feldman MA, Walton-Allen N 1997 Effects of maternal mental retardation and poverty on intellectual, academic, and behavioral status of school-age children. Am J Ment Retard 101:352-364

2. O'Neill AM 1985 Normal and bright children of mentally retarded parents: the Huck Finn syndrome. Child Psychiatry Hum Dev 15:255-268

3. Goodman R, Simonoff E, Stevenson J 1995 The impact of child IQ, parent IQ and sibling IQ on child behavioural deviance scores. J Child Psychol Psychiatry 36:409_ 425

4. Andersson HW, Sommerfelt K 2001 The relationship between cognitive abilities and maternal ratings of externalizing behaviors in preschool children. Scand J Psychol 42:437-444

5. Anselmi L, Piccinini CA, Barros FC, Lopes RS 2004 Psychosocial determinants of behaviour problems in Brazilian preschool children. J Child Psychol Psychiatry 45:779-788

6. 1998 The Treatment of Lead-exposed Children (TLC) trial: design and recruitment for a study of the effect of oral chelation on growth and development in toddlers. Paediatr Perinat Epidemiol 12:313-333

7. Rogan WJ, Dietrich KN, Ware JH, Dockery DW, Salganik M, Radcliffe J, Jones RL, Ragan NB, Chisolm Jr, JJ Rhoads GG 2001 The effect of chelation therapy with succimer on neuropsychological development in children exposed to lead. N Engl J Med 344:1421-1426

8. Dietrich KN, Ware JH, Salganik M, Radcliffe J, Rogan WJ, Rhoads GG, Fay ME, Davoli CT, Denckla MB, Bornschein RL, Schwarz D, Dockery DW, Adubato S, Jones RL Treatment of Lead-Exposed Children Clinical, Trial Group 2004 Effect of chelation therapy on the neuropsychological and behavioral development of leadexposed children after school entry. Pediatrics 114:19-26

9. Silverstein AB 1985 Two- and four-subtest short forms of the WAIS-R: a closer look at validity and reliability. J Clin Psychol 41:95-97

10. Wechsler D 1989 The Wechsler Preschool and Primary Scales of IntelligenceRevised. The Psychological Corporation, San Antonio, TX

11. Wechsler D 1991 Wechsler Intelligence Scale for Children-III. The Psychological Corporation, San Antonio, TX 
12. Korkman M, Kirk U, Kemp S 1998 NEPSY: A Developmental Neuropsychological Assessment: Manual. Rev. The Psychological Corporation, San Antonio, TX

13. Conners CK 1997 Conners' Rating Scales: Technical Manual. Multi-Health Systems, North Tonawanda, NY

14. Conners CK 1995 Conners' Continuous Performance Test. Multi-Health Systems, North Tonawanda, NY

15. Delis DC, Kramer JH, Kaplan E, Ober BA 1994 California Verbal Learning Test-Children's Version. The Psychological Corporation, San Antonio, TX

16. Woodcock RW 1991 Woodcock Language Proficiency Battery-Revised. Riverside Publishing, Itasca, IL

17. Denckla MB 1985 Revised Neurological Examination for Subtle Signs Psychopharmacol Bull 21:773-800

18. Reynolds CR, Kamphaus RW 1992 Behavior Assessment System for Children. American Guidance Service, Circle Pines, MN

19. Miller DT, Paschal DC, Gunter EW, Stroud PE, D'Angelo J 1987 Determination of lead in blood using electrothermal atomisation atomic absorption spectrometry with a L'vov platform and matrix modifier. Analyst 112:1701-1704

20. Burns JM, Baghurst PA, Sawyer MG, McMichael AJ, Tong SL 1999 Lifetime low-level exposure to environmental lead and children's emotional and behavioral development at ages 11-13 years. The Port Pirie Cohort Study. Am J Epidemiol 149:740-749

21. Wasserman GA, Staghezza-Jaramillo B, Shrout P, Popovac D, Graziano J 1998 The effect of lead exposure on behavior problems in preschool children. Am J Public Health 88:481-486

22. Sciarillo WG, Alexander G, Farrell KP 1992 Lead exposure and child behavior. Am J Public Health 82:1356-1360

23. Bacharach VR, Baumeister AA 1998 Effects of maternal intelligence, marital status, income, and home environment on cognitive development of low birthweight infants. J Pediatr Psychol 23:197-205

24. Plomin R 1999 Genetics and general cognitive ability. Nature 402:C25-29

25. Stoolmiller M 1999 Implications of the restricted range of family environments for estimates of heritability and nonshared environment in behavior-genetic adoption studies. Psychol Bull 125:392-409

26. Dickens WT, Flynn JR 2001 Heritability estimates versus large environmental effects: the IQ paradox resolved. Psychol Rev 108:346-369

27. Gillberg C, Geijer-Karlsson M 1983 Children born to mentally retarded women: a 1-21 year follow-up study of 41 cases. Psychol Med 13:891-894
28. Feldman MA, Case L, Towns F, Betel J 1985 Parent Education Project. I: development and nurturance of children of mentally retarded parents. Am J Ment Defic 90:253-258

29. Schwartz J 1994 Low-level lead exposure and children's IQ: a meta-analysis and search for a threshold. Environ Res 65:42-55

30. Pocock SJ, Smith M, Baghurst P 1994 Environmental lead and children's intelligence: a systematic review of the epidemiological evidence. BMJ 309:1189-1197

31. Lanphear BP, Hornung R, Khoury J, Yolton K, Baghurst P, Bellinger DC, Canfield RL, Dietrich KN, Bornschein R, Greene T, Rothenberg SJ, Needleman HL, Schnaas L, Wasserman G, Graziano J, Roberts R 2005 Low-level environmental lead exposure and children's intellectual function: an international pooled analysis. Environ Health Perspect 113:894-899

32. Offord DR, Boyle MH, Szatmari P, Rae-Grant NI, Links PS, Cadman DT, Byles JA, Crawford JW, Blum HM, Byrne C, et al 1987 Ontario Child Health Study. II. Six-month prevalence of disorder and rates of service utilization. Arch Gen Psychiatry $44: 832-836$

33. Deng S, Liu X, Roosa MW 2004 Agreement between parent and teacher reports on behavioral problems among Chinese children. J Dev Behav Pediatr 25:407-414

34. Kumpulainen K, Rasanen E, Henttonen I, Moilanen I, Piha J, Puura K, Tamminen T, Almqvist F 1999 Children's behavioural/emotional problems: a comparison of parents' and teachers' reports for elementary school-aged children. Eur Child Adolesc Psychiatry 8 (suppl 4):41-47

35. Gagnon C, Vitaro F, Tremblay RE 1992 Parent-teacher agreement on kindergarteners' behavior problems: a research note. J Child Psychol Psychiatry 33:1255-1261

36. Harder DW, Greenwald DF 1992 Parent, family interaction, and child predictors of outcome among sons at psychiatric risk. J Clin Psychol. 48:151-164

37. Greenwald DF 1990 Child functioning predictors of outcome among boys at risk for psychological disorder. J Genet Psychol 151:139-151

38. Schachar R, Rutter M, Smith A 1981 The characteristics of situationally and pervasively hyperactive children: implications for syndrome definition. J Child Psychol Psychiatry 22:375-392

39. Broman S, Nichols PL, Shaughnessy P, Kennedy W 1987 Retardation in Young Children: A Developmental Study of Cognitive Deficit. Lawrence Erlbaum Associates, Hillsdale, NJ, pp 24-37

40. Renick MJ, Harter S 1989 Impact of social comparisons on the developing selfperceptions of learning disabled students. J Educ Psychol 81:631-638 